\title{
EFFECTS OF SPAN MORPHING ON FLUTTER CHARACTERISTICS OF SUBSONIC WING
}

\author{
Damla Durmuş ${ }^{1}$ and Metin O. Kaya ${ }^{1}$ \\ ${ }^{1}$ Istanbul Technical University, Department of Aeronautical Engineering \\ 34469 Maslak, Istanbul, Turkey \\ durmus17@itu.edu.tr, kayam@itu.edu.tr
}

Key words: Aeroelasticity, Flutter, Span-Morphing Wings, Differential Transformation Method.

\begin{abstract}
This paper focuses on the dynamic behavior of variable-span morphing wings (VSMW) oscillating in pitch and plunge motions under subsonic flight conditions. The unswept cantilevered wing is modeled as three-stepped Euler-Bernoulli beam. The aerodynamic loads acting on the wing are represented by Theodorsen's unsteady aerodynamic theory. The differential equations of motion that describe the behavior of the dynamics of Euler-Bernoulli beam are derived through the Hamilton's principle. The differential transformation method (DTM) is implemented to equations of motion and boundary conditions. The solution of the aeroelastic system is obtained by the classical frequency domain solution, $k$-method. Goland wing and High-Altitude Long-Endurance (HALE) wing are used as the basis for this study. Prior to analyzing flutter characteristics of VSMW, validation cases are conducted to ensure that the developed algorithm works well. Furthermore, flutter speed and flutter frequency are analyzed for different elongation ratios of wing. There is a significant difference in flutter values of fully retracted and fully extended wing configurations. It can be concluded that both flutter speed and flutter frequency decrease dramatically as wing span extends. Another important finding is that the flutter speed and flutter frequency reductions are relatively high at the initial stages of wing span extension.
\end{abstract}

\section{INTRODUCTION}

Morphing wing technology has gained a great deal of attention in the scientific area due to its capability to perform multi-role missions. The telescopic span morphing mechanism has ability to change wing span in order to achieve better aircraft performance, enlarge the flight envelope and accomplish multiple mission roles at different phases of flight. Moreover, asymmetrical wing span extension provides roll control as an alternative to aileron control surfaces. Aeroelasticity is the field of study that is concerned with the effects of interactions among aerodynamic, elastic and inertial forces on aircraft structures [1]. Flutter is an aeroelastic dynamic instability condition that affects the overall safety, flight performance and energy efficiency of an aircraft. The flutter characteristics of span morphing wings should be investigated with utmost attention. The motivation behind this study is contributing to this growing area by analyzing the flutter behavior of morphing wings.

Several investigations were performed to explore the aeroelastic characteristics of VSMW up to now. Most of the span morphing concept are based on a telescopic mechanism which is introduced by Ivan Mahhonine [2]. In 1931, first known examination of the telescopic span morphing wing was conducted via the Makhonine Mak-10 aircraft. 
Ajaj et al. [3] investigated the aeroelastic behavior of VSMW. In their research, the effects of span morphing on flutter are analyzed in detail. It is pointed out that the span morphing can act as a flutter suppression device if high actuation rates are used to prevent large amplitudes oscillation. Gamboa et al. [4] also studied the aeroelastic behavior of VSMW. They obtained mode shapes, natural frequencies and flutter speed of a small UAV. The aerodynamic and static aeroelastic characteristics of VSMW of a long-range cruise missile are analyzed by Seigler et al. [5]. Huang and Qui [6] investigated the transient aeroelastic responses and flutter characteristics of VSMW during the morphing process. The result of their studies presented that the flutter speed increases with increasing morphing speed during extension process. It is also stated that the morphing technology would be a potential flutter control approach. Huang and Yang et al. [7] investigated the significance of rigid-body motions for flutter behavior of VSMW. It is suggested that the rigid-body motions should be included in the flutter analysis of VSMW.

\section{STRUCTURAL AND AERODYNAMIC MODELING}

The unswept cantilevered wing is modeled as an Euler-Bernoulli beam which is a widely preferred model to simplify the wing structural model. The kinetic and potential energies of Euler-Bernoulli beam are expressed in Eqs. (1)-(2), respectively.

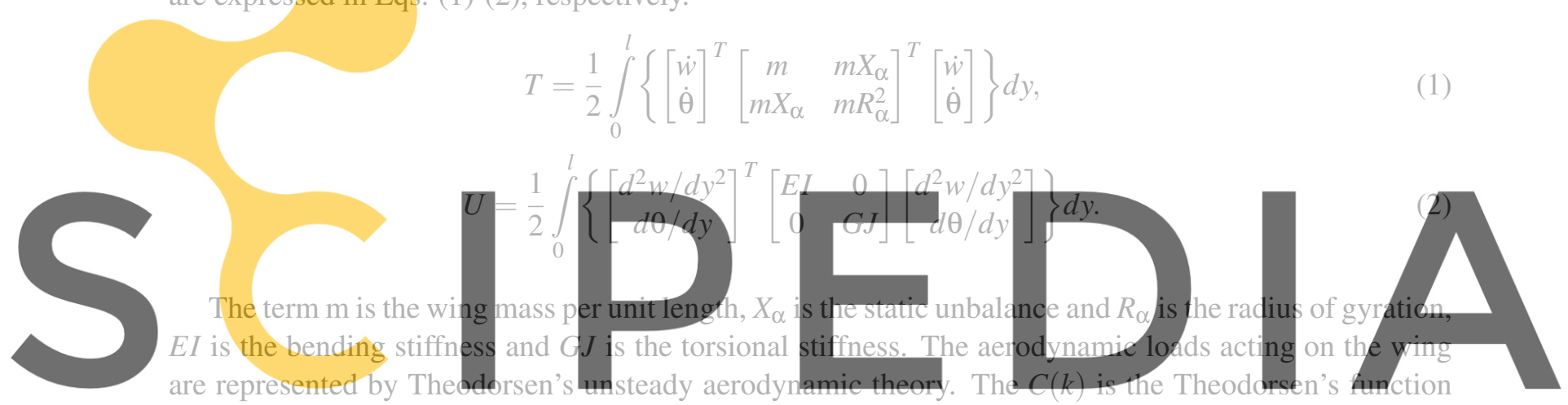

which is a complex-valued function of the reduced frequency. It consists of complex and real parts such

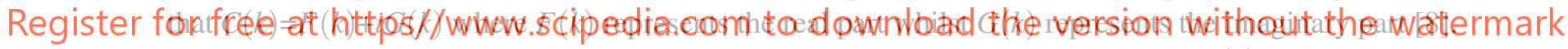

The aerodynamic lift and moment expressions are given in Eqs. (3)-(4) in terms of $C(k)$, respectively.

$$
\begin{gathered}
L=2 \pi \rho_{\infty} U_{\infty} b C(k)\left[\dot{w}+U_{\infty} \theta+b\left(\frac{1}{2}-a\right) \dot{\theta}\right]+\pi \rho_{\infty} b^{2}\left(\ddot{w}+U_{\infty} \dot{\theta}-b a \ddot{\theta}\right), \\
M=b\left(\frac{1}{2}+a\right)\left\{2 \pi \rho_{\infty} U_{\infty} b C(k)+\left[\dot{w}+U_{\infty} \theta+b\left(\frac{1}{2}-a\right) \dot{\theta}\right]\right. \\
\left.+\pi \rho_{\infty} b^{2}\left(\ddot{w}+U_{\infty} \dot{\theta}-b a \ddot{\theta}\right)\right\}-\pi \rho_{\infty} b^{3}\left[\frac{1}{2} \ddot{w}+U_{\infty} \dot{\theta}+b\left(\frac{1}{8}-\frac{a}{2}\right) \ddot{\theta}\right],
\end{gathered}
$$

where $\rho_{\infty}$ is the air density, $U_{\infty}$ is air stream velocity and $a$ is the elastic axis location. Hamilton's principle is utilized in order to obtain the equations of motion that are expressed in Eqs. (5)-(6).

$$
\begin{gathered}
-\frac{d^{2}}{d y^{2}}\left(E I \frac{d^{2} w}{d y^{2}}\right)+m \frac{d^{2} w}{d t^{2}}+m X_{\theta} \frac{d^{2} \theta}{d t^{2}}-L=0, \\
\frac{d}{d y}\left(G J \frac{d \theta}{d y}\right)+m R_{\theta}^{2} \frac{d^{2} \theta}{d y^{2}}+m X_{\theta} \frac{d^{2} w}{d t^{2}}+M=0 .
\end{gathered}
$$


It is assumed that the motions in both bending and torsion are harmonic. The exponential function of time is used as the general solution to Eqs. (5)-(6). The finalized equations of motion in nondimensional form are obtained by exponential solution function as following,

$$
\begin{gathered}
-\mu \lambda_{1}^{4} \frac{1}{\omega^{2}} \frac{d^{4} w}{d \xi^{4}}+\mu w+\mu \frac{X_{\theta}}{b} \theta-l_{w} w-l_{\theta}=0, \\
-\mu \lambda_{2}^{2} \frac{1}{\omega^{2}} \frac{d^{2} \theta}{d \xi^{2}}+\mu \frac{X_{\theta}}{b} w+\mu \frac{R_{\theta}^{2}}{b^{2}} \theta+m_{w} w+m_{\theta} \theta=0,
\end{gathered}
$$

where $b$ is the semi-chord length. $\lambda_{1}^{4}, \lambda_{2}^{2}$ and $\mu$ are employed for simplicity and expressed as following,

$$
\lambda_{1}^{4}=\frac{E_{0} I_{0}}{m l^{4}}, \quad \quad \lambda_{2}^{2}=\frac{G_{0} J_{0}}{m l^{2}}, \quad \mu=\frac{m}{\pi \rho_{\infty} b^{2}} .
$$

The complex dimensionless aerodynamic lift and moment coefficients $l_{w}, l_{\theta}, m_{w}$ and $m_{\theta}$ are listed as,

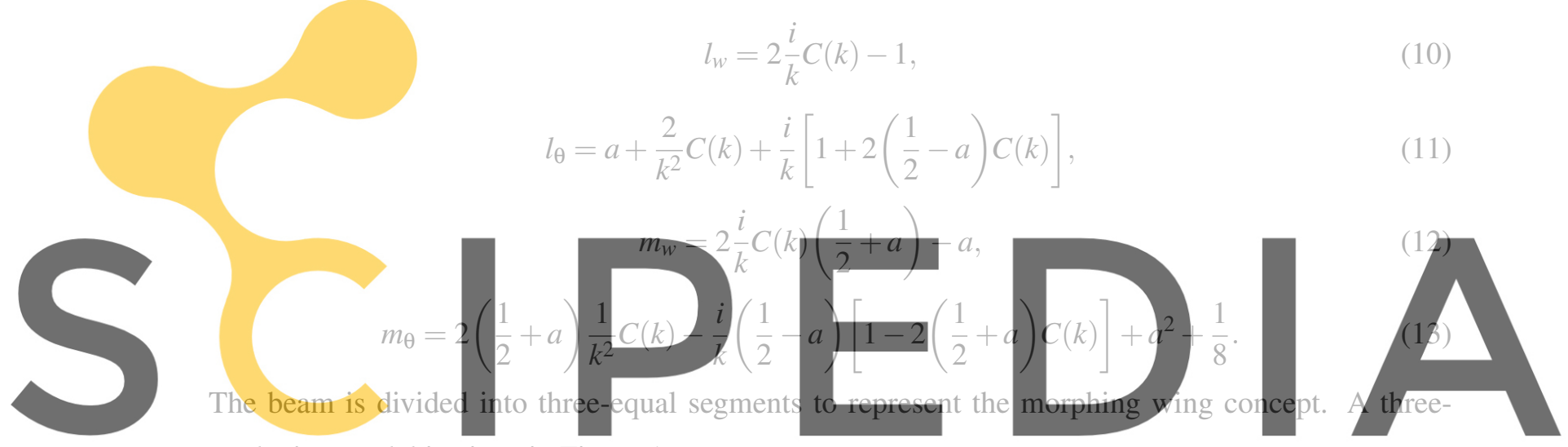

stepped wing model is given in Figure 1.

Register for free at https//www.scipedia.com to download the version without the watermark

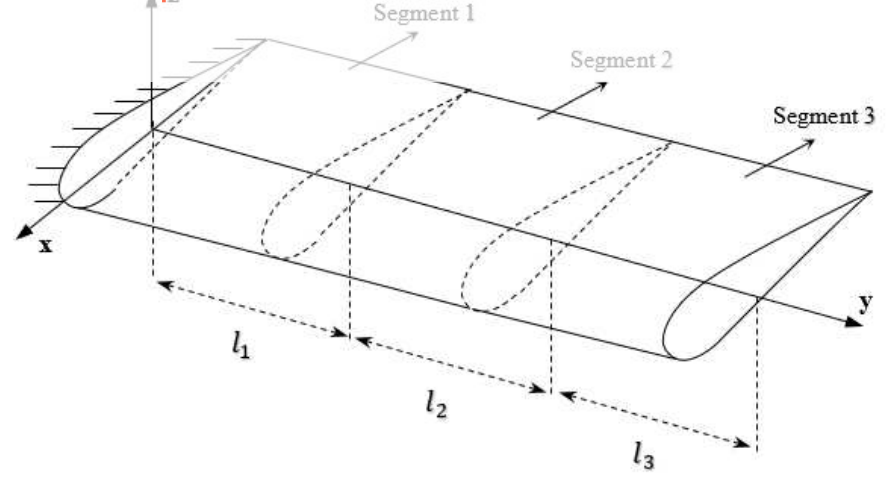

Figure 1: Schematic view of the three-stepped wing model.

The boundary conditions of three-stepped beam for bending and torsion motions are given in Table 1 as following, 
Table 1: Bending and torsion boundary conditions of three-stepped beam model.

\begin{tabular}{llll}
\hline \multicolumn{2}{c}{ Fixed end } & \multicolumn{2}{c}{ Free end } \\
\hline Bending & Torsion & Bending & Torsion \\
\hline \multirow{2}{*}{$w_{1}=0$} & \multirow{2}{*}{$\theta_{1}=0$} & $\frac{d^{2} w_{3}}{d y^{2}}=0$ & $\frac{d \theta_{3}}{d y_{3}}=0$ \\
\hline$\frac{d w_{1}}{d y_{1}}$ & & $\frac{d^{3} w_{3}}{d y^{3}}=0$ & \\
\hline
\end{tabular}

The bending and torsion continuity conditions of three-stepped beam at $y=l_{i}$, where $i=1,2$, are given in Table 2.

Table 2: Bending and torsion continuity conditions of stepped beam model.

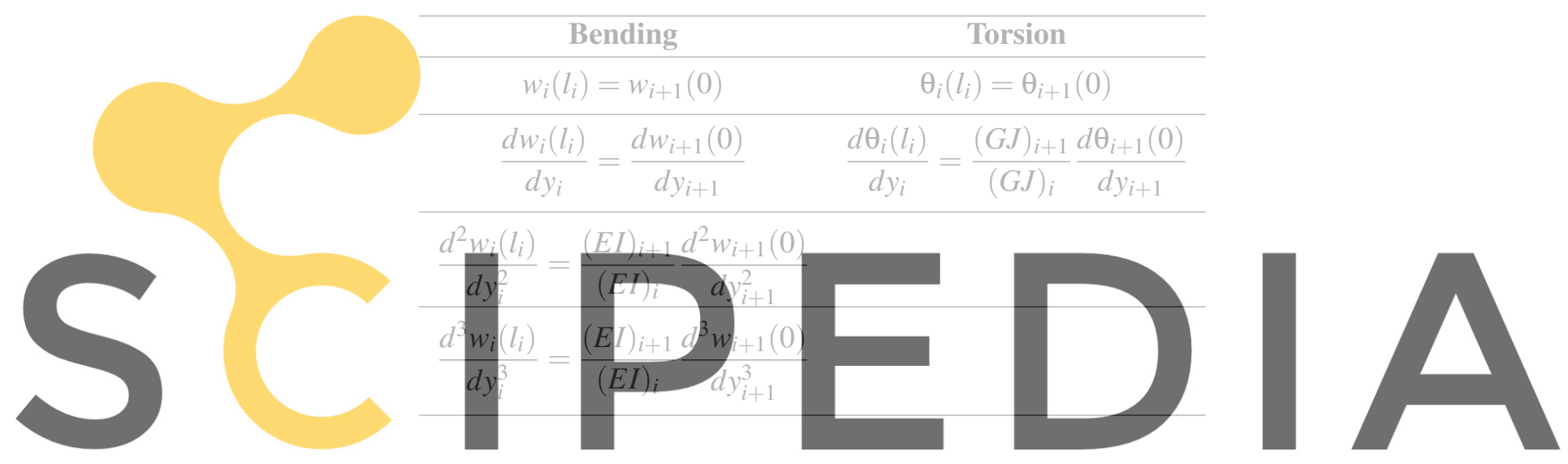

3 DIFFERENTIAL TRANSFORMATION METHOD

Register for free at https//www.scipedia.com to download the version without the watermark

DTM is a powerful mathematical technique for solving ordinary and partial differential equations

which can be applied to many engineering problems to obtain analytical solutions [9]. This method is

basically based on Taylor series expansion. The main distinction between the present technique and the Taylor series method is that the DTM has the capability of decreasing the size of computational work.

Let $f(x)$ be an analytical function in $\mathrm{K}$ domain and $x=x_{0}$ represent any point in $K$. Thus, the function $f(x)$ can be defined by a power series where the center is at $x_{0} . F(k)$ is referred to as the $k^{t h}$ order transformed function of original function $f(x)$ about the point $x=x_{0}$,

$$
F(k)=\frac{1}{k !}\left[\frac{d^{k} f(x)}{d x^{k}}\right]_{x=x_{0}} .
$$

The inverse differential transform of the $f(x)$ :

$$
f(x)=\sum_{k=0}^{\infty}\left(x-x_{0}\right)^{k} F_{k} .
$$

Putting together Eq. 14-15: 


$$
f(x)=\sum_{k=0}^{\infty} \frac{\left(x-x_{0}\right)^{k}}{k !}\left[\frac{d^{k} f(x)}{d x^{k}}\right]_{x=x_{0}},
$$

which is actually the expansion of the Taylor series for $f(x)$ about $x-x_{0}$.

Mathematical operations conducted by DTM are given in Table 3. Using these rules, governing equations are transformed into new expressions.

Table 3: Main operations of the DTM.

\begin{tabular}{cc}
\hline Original Function & Transformed Function \\
\hline$f(x)=u(x) \pm v(x)$ & $F(k)=U(k) \pm V(k)$ \\
\hline$f(x)=a u(x)$ & $F(k)=a U(k)$ \\
$f(x)=\frac{d u(x)}{d x}$ & $F(k)=(k+1) U(k+1)$ \\
\hline$f(x)=\frac{d^{m} u(x)}{d x^{m}}$ & $F(k)=\sum_{l=0}^{k} V(l) U(k-l)$ \\
\hline$f(x)=u(x) v(x)$ &
\end{tabular}
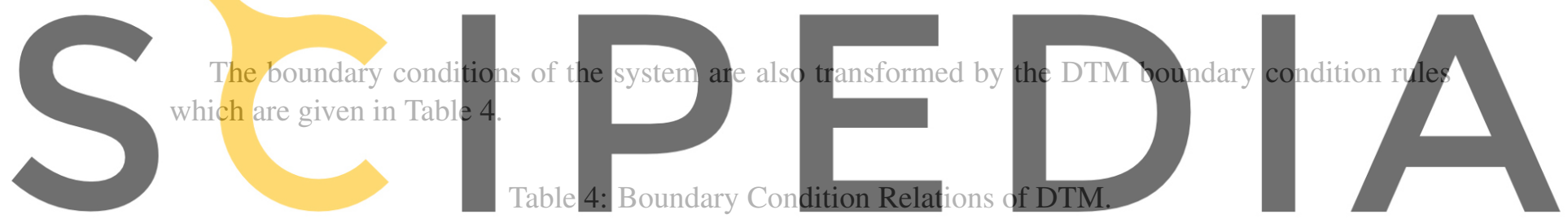

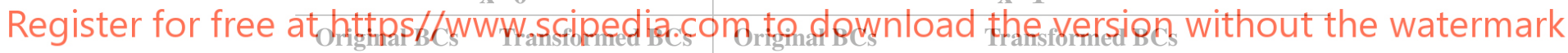

\begin{tabular}{ll|ll}
\hline$f(0)=0$ & $F(0)=0$ & $f(1)=0$ & $\sum_{k=0}^{\infty} F(k)=0$ \\
\hline$\frac{d f}{d x}(0)=0$ & $F(1)=0$ & $\frac{d f}{d x}(1)=0$ & $\sum_{k=0}^{\infty} k \cdot F(k)=0$ \\
\hline$\frac{d^{2} f}{d x^{2}}(0)=0$ & $F(2)=0$ & $\frac{d^{2} f}{d x^{2}}(1)=0$ & $\sum_{k=0}^{\infty} k \cdot(k-1) F(k)=0$ \\
\hline$\frac{d^{3} f}{d x^{3}}(0)=0$ & $F(3)=0$ & $\frac{d^{3} f}{d x^{3}}(1)=0$ & $\sum_{k=0}^{\infty} k \cdot(k-1) \cdot(k-2) F(k)=0$ \\
\hline
\end{tabular}

The k-method, which is also known as American method, is utilized for the solution of aeroelastic system. In this method, artificial damping parameter $\mathrm{g}$ is introduced to calculate the flutter speed of the system.

$$
Z=\frac{1+i g}{\omega^{2}}
$$


For the given specified reduced frequencies, the solution of the Eqs. (7)-(8) gives $Z$. After $Z$ is calculated, the frequency $\omega_{i}$, the artificial damping $g$, and the flight speed $V_{i}$ can be calculated from the following expressions,

$$
\begin{gathered}
\omega_{i}=\frac{1}{\sqrt{\operatorname{Re}(Z)}}, \\
g=\frac{\operatorname{Im}(Z)}{\operatorname{Re}(Z)}, \\
V_{i}=\frac{\omega_{i} b}{k} .
\end{gathered}
$$

\subsection{Application of the differential transformation method}

DTM rules are applied to the aeroelastic equations of motion, which are given in equation Eqs. (7)(8), the transformed equations of motion are given in the following expressions,

$$
\bar{w}[m+4]=\frac{Z}{\lambda_{1}^{4}}\left(\frac{\bar{w}[m]+\bar{X}_{\theta} \bar{\theta}[m]-\frac{l_{w}}{\mu} \bar{w}[m]-\frac{l_{\theta}}{\mu} \bar{w}[m]}{(m+4)(m+3)(m+2)(m+1)}\right),
$$
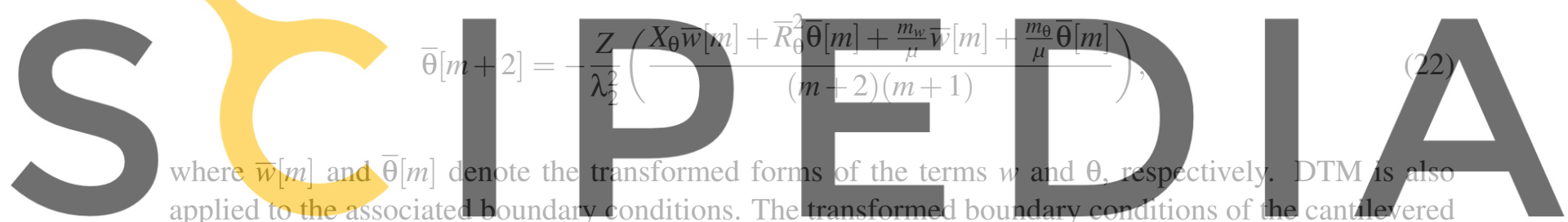

applied to the associate boundary conditions. Th
Euler-Bernoulli beam are given in Eqs. (23)-(26),

Register for free at https//www.scipedia.com to download the version without the watermark

$$
\bar{w}(0)=\bar{w}(1)=\bar{\theta}(0)=0 \text {, }
$$

$$
\begin{gathered}
\sum_{k=0}^{\infty} k \cdot(k-1) \bar{w}(k)=0, \\
\sum_{k=0}^{\infty} k \cdot(k-1) \cdot(k-2) \bar{w}(k)=0, \\
\sum_{k=0}^{\infty} k \bar{\theta}(k)=0 .
\end{gathered}
$$




\section{NUMERICAL RESULTS}

\subsection{Verification of the numerical method}

To validate the accuracy and reliability of the developed algorithm, two wing types that are well known in literature, Goland and HALE wings, are taken into consideration. The structural and geometrical properties of Goland and HALE wings are given in Table 5.

Table 5: The structural and geometrical properties of Goland and HALE wings.

\begin{tabular}{lccc}
\hline Parameter & Unit & Goland wing & HALE wing \\
\hline Half span $(l)$ & $m$ & 6.096 & 16 \\
\hline Chord $(l)$ & $m$ & 1.8288 & 1 \\
\hline Bending rigidity $(E I)$ & $N . m^{2}$ & $9.77 \times 10^{6}$ & $2 \times 10^{14}$ \\
\hline Torsional rigidity $(G J)$ & $N \cdot \mathrm{m}^{2}$ & $0.987 \times 10^{6}$ & $1 \times 10^{14}$ \\
\hline Wing mass per unit length $(m)$ & $\mathrm{kg} / \mathrm{m}$ & 35.71 & 0.75 \\
\hline Mass moment of inertia about elastic axis per unit length $\left(I_{E A}\right)$ & $\mathrm{kg} \cdot \mathrm{m}$ & 8.64 & 0.1 \\
\hline Elastic axis position from leading edge $\left(y_{0}\right)$ & $m$ & $0.33 c$ & $0.5 \mathrm{c}$ \\
\hline Static Unbalance & $\mathrm{kg}$ & 6.523 & 0
\end{tabular}

By implementing the parameters of Goland and HALE wings into the devoloped code, the flutter
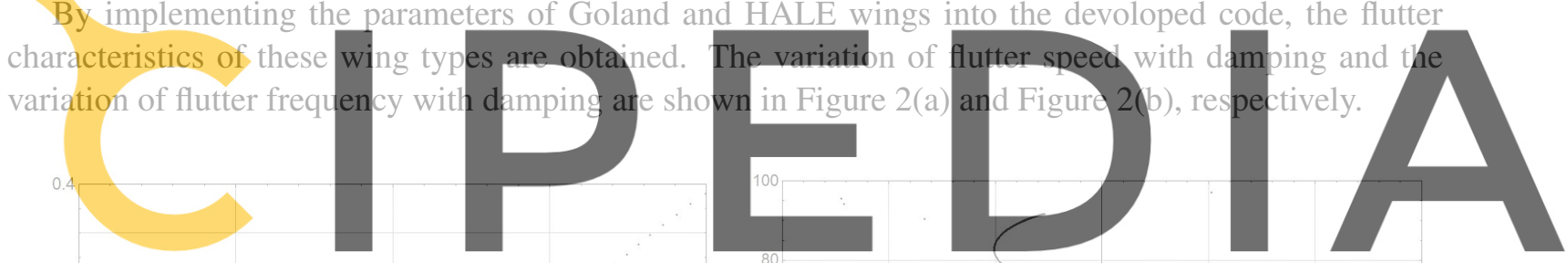

Register for free at https//www.scipedia.com to download the version without the watermark

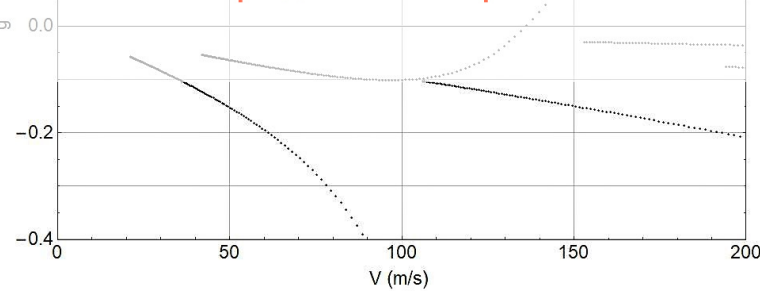

(a)

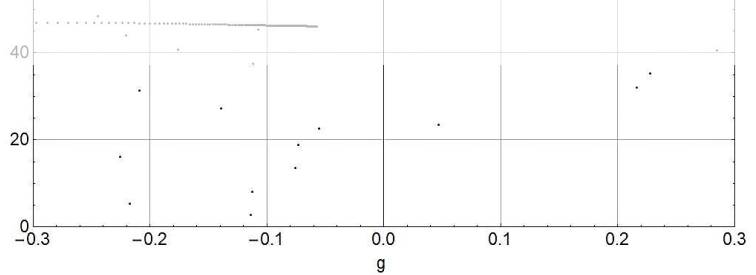

(b)

Figure 2: $V-g$ and $\omega-g$ plots for Goland wing.

$V-g$ plot gives an estimation of dynamic behaviour of the system easily. The instability is occured at $V=136.10 \mathrm{~m} / \mathrm{s}$. Table 6 compares flutter speed and flutter frequency with data from reference study for Goland wing. 
Table 6: The comparison of flutter results for the Goland wing.

\begin{tabular}{lccc}
\hline Critical values for flutter & Present study & Reference study [10] & Error $(\%)$ \\
\hline Flutter speed, $\mathrm{m} / \mathrm{s}$ & 136.10 & 137.16 & 0.77 \\
\hline Flutter frequency, $\mathrm{rad} / \mathrm{s}$ & 70.01 & 70.70 & 0.97 \\
\hline
\end{tabular}

Similar investigations are also performed by Matter et al. [11] and Patil et al. [12]. Matter et al. [11] investigated the flutter characteristics of Goland wing by Galerkin method. They found the flutter speed as $136.41 \mathrm{~m} / \mathrm{s}$ and flutter frequency as $69.35 \mathrm{rad} / \mathrm{s}$. Patil et al. [12] also analyzed the flutter boundaries of Goland wing. They reported the flutter speed as $137.16 \mathrm{~m} / \mathrm{s}$ and the flutter frequency as $70.2 \mathrm{rad} / \mathrm{s}$ which are very close to findings of current study.

Flutter speed and frequency values of HALE wing are obtained by observing the relevant plots of the system. By developed algorithm, the graphs of flutter analysis with respect to velocity, frequency and damping are obtained which are given in Figure 3.

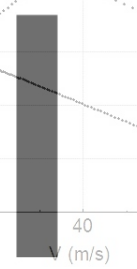

(a)

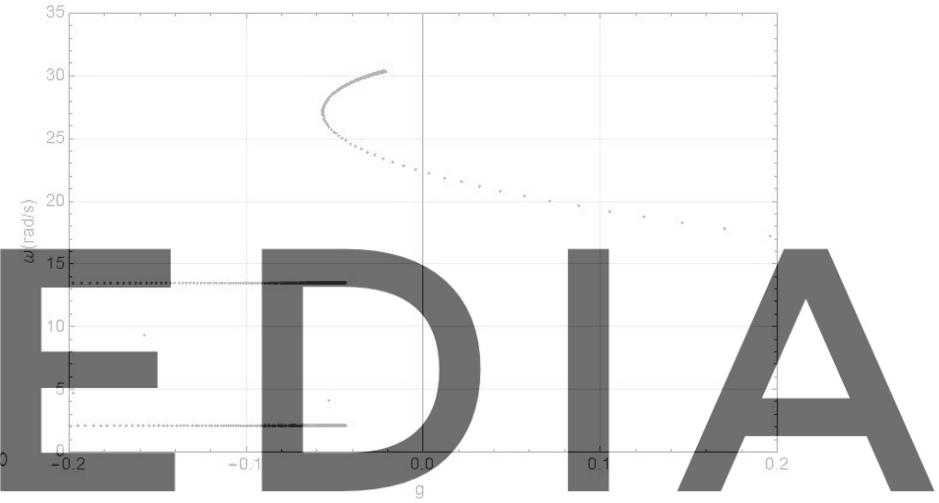

(b)

Register for free at https//www.scipedia.com to download the version without the watermark Figure 3: $V-g$ and $\omega-g$ plots for HALE wing.

The flutter speed and the flutter frequency of HALE wing are found as $32.22 \mathrm{~m} / \mathrm{s}$ and $22.39 \mathrm{rad} / \mathrm{s}$, respectively. The flutter values of HALE wing are compared with literature in Table 7.

Table 7: The comparison of flutter results for the HALE wing.

\begin{tabular}{lccc}
\hline Critical values for flutter & Present study & Reference study [13] & Error $(\boldsymbol{\%})$ \\
\hline Flutter speed, $\mathrm{m} / \mathrm{s}$ & 32.22 & 32.21 & 0.03 \\
\hline Flutter frequency, $\mathrm{rad} / \mathrm{s}$ & 22.39 & 22.61 & 0.97 \\
\hline
\end{tabular}

It can be seen from Table 7 that the findings of current study are in excellent agreement with values from reference study. 


\subsection{Goland wing at $50 \%$ span extension}

Flutter behavior of Goland wing at 50\% extension is analyzed and validated with study from literature [3]. In this configuration, the wing span extends by 50\%, thus the semi-span length becomes $9.144 \mathrm{~m}$. A schematic view of the wing at 50\% extension is illustrated in Figure 4.

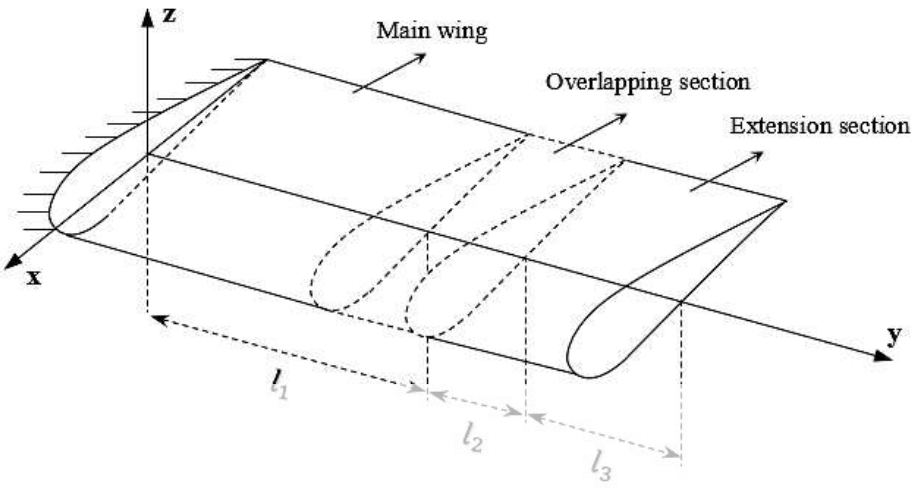

Figure 4: A schematic view of the VSMW.

For 50\% extended Goland wing, the half span of wing is the only parameter that changes. All other parameters remain the same since they are related with cross-section of the wing. The length of first

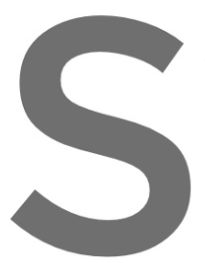
segment is $l_{1}=5 \mathrm{~m}$, seco
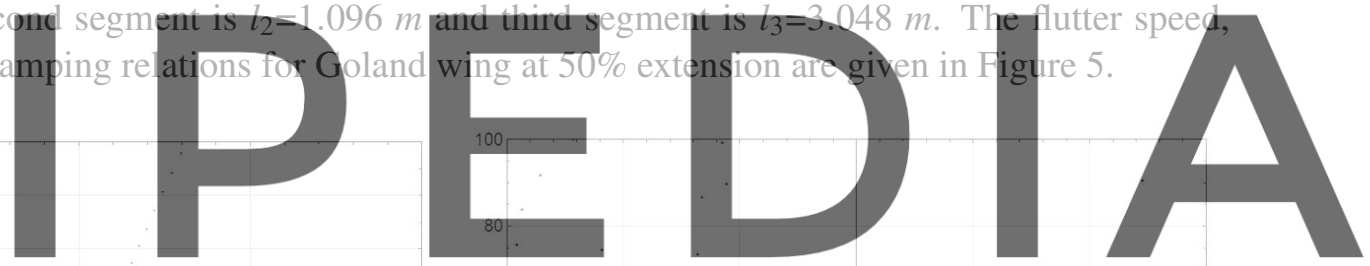

Register for free at https//www.scipedia.com to download the version without the watermark

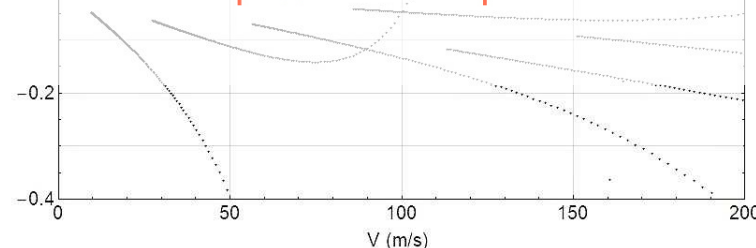

(a)

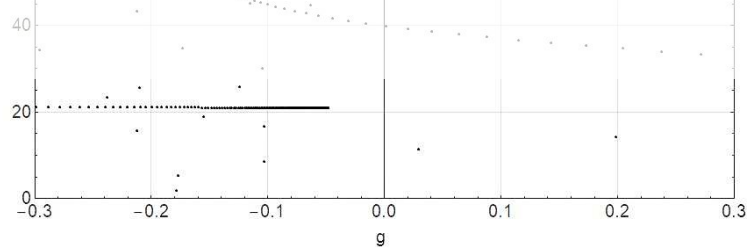

(b)

Figure 5: $V-g$ and $\omega-g$ plots for Goland wing at 50\% extension.

Ajaj et al. [3] reported the flutter speed of Goland wing at 50\% extension is at around $100 \mathrm{~m} / \mathrm{s}$. In the current study, the flutter speed is found as $104.1 \mathrm{~m} / \mathrm{s}$ with the error $3.93 \%$. The flutter speed of Goland wing is found as $136.10 \mathrm{~m} / \mathrm{s}$ in Section 4.1. Taken together, these findings show that flutter speed decreases as the wing span extends.

The flutter frequency is found as $39.9 \mathrm{rad} / \mathrm{s}$ at a point where $g$ takes a value 0 . At one-segment Goland wing model, the flutter frequency was found to be $70.01 \mathrm{rad} / \mathrm{s}$. As is the case with the flutter 
speed, the flutter frequency also decreases as wing span extends.

The flutter values of $50 \%$ extended and $0 \%$ extended wings are also given in a compact form. The flutter speed and frequency are compared for both two configurations in Table 8.

Table 8: The comparison of flutter values of Goland wing at 50\% and $0 \%$ span extension.

\begin{tabular}{lcc}
\hline Critical values for flutter & $\mathbf{0 \%}$ extension & $\mathbf{5 0 \%}$ extension \\
\hline Flutter speed, $\mathrm{m} / \mathrm{s}$ & 136.10 & 104.1 \\
\hline Flutter frequency, $\mathrm{rad} / \mathrm{s}$ & 70.01 & 39.9 \\
\hline
\end{tabular}

\subsection{HALE wing at $50 \%$ span extension}

After validating the flutter characteristics of Goland wing at 50\% span extension, HALE wing at $50 \%$ extension is also investigated. The lengths of first and second segments are assigned by author. The length of first segment is taken as $l_{1}=13.333 \mathrm{~m}$ whilst the length of second segment is taken as $l_{2}=2.667$ $m$. Thus, the length of third segment of the HALE wing is taken as $l_{3}=8 \mathrm{~m}$. The variation of the speed with damping and the variation of frequency with damping of HALE wing at 50\% extension are given in Figure 6(a) and Figure 6(b), respectively.
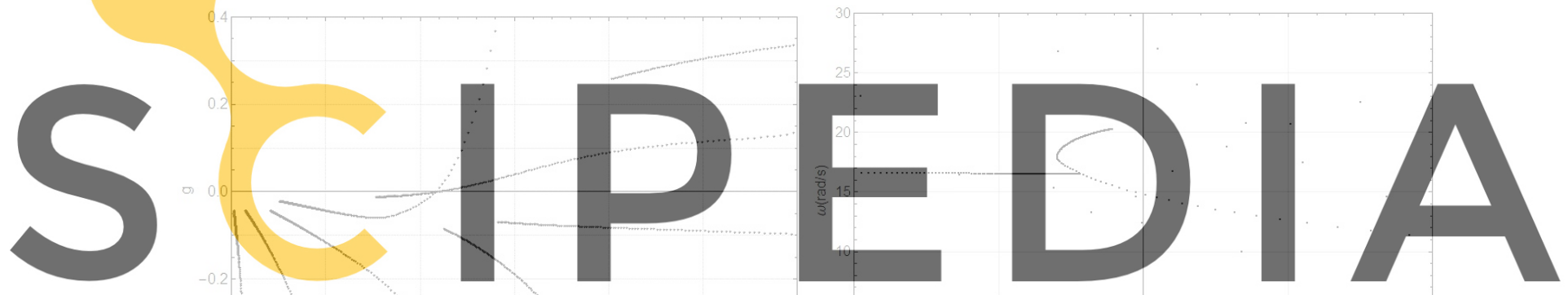

Register for free at https//www.scipedia.com to download the version without the watermark

(a)

(b)

Figure 6: $V-g$ and $\omega-g$ plots for HALE wing at $50 \%$ extension.

As the HALE wing span extends by $50 \%$, the flutter speed and flutter frequency decrease to 21.47 $\mathrm{m} / \mathrm{s}$ and $14.75 \mathrm{rad} / \mathrm{s}$, respectively. The comparison of flutter values for HALE wing at 50\% extension configuration with $0 \%$ extension configuration is given in Table 9.

Table 9: The comparison of flutter values of HALE wing at 50\% and $0 \%$ span extension.

\begin{tabular}{lcc}
\hline Critical values for flutter & $\mathbf{0 \%}$ extension & $\mathbf{5 0 \%}$ extension \\
\hline Flutter speed, $\mathrm{m} / \mathrm{s}$ & 32.22 & 21.47 \\
\hline Flutter frequency, $\mathrm{rad} / \mathrm{s}$ & 22.39 & 14.75 \\
\hline
\end{tabular}


It can be easily seen from Table 9 that the flutter speed and the flutter frequency decrease dramatically as expected when the wing span extends by $50 \%$.

\subsection{Effects of VSMW on Flutter Behavior}

The flutter speed is investigated for different span extensions of Goland wing. The variation of flutter speed with various wing extension percentages is shown in Figure 7.

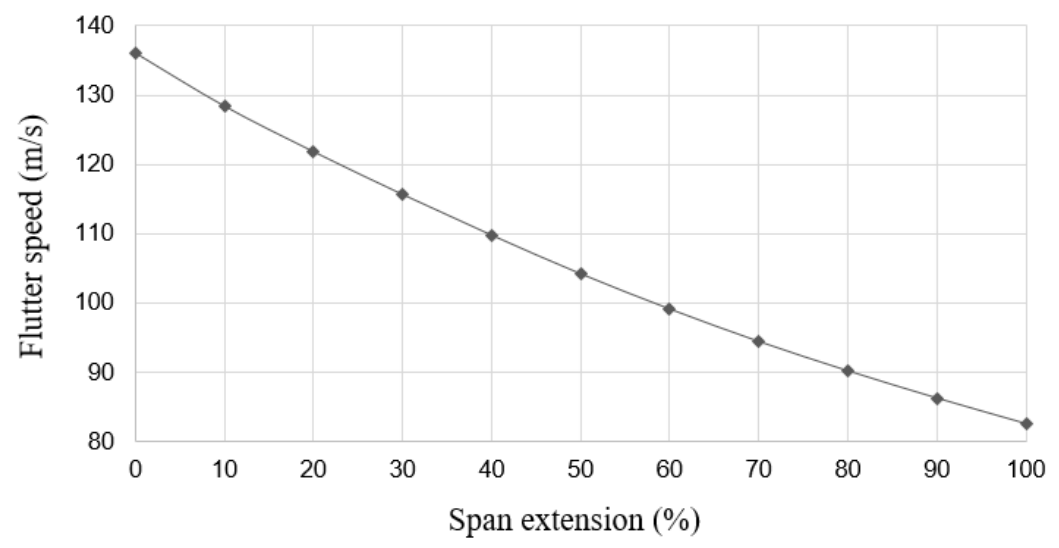

Figure 7: Variation of flutter speed with span extension for Goland wing.

As Figure 7 presents, there is a significant difference in flutter speed between fully retracted and fully extended wing configurations. When the wing extends its span by $100 \%$, the flutter speed decreases to $82.4 \mathrm{~m} / \mathrm{s}$. It is apparent that flutter speed decreases dramatically as wing span extends.

The flutter frequencies are obtained for different elongation ratios of the wing span. The VSMW mechanism also considerably effects the flutter frequency of system. The variation of flutter frequency with span extension is given in Figure 8.

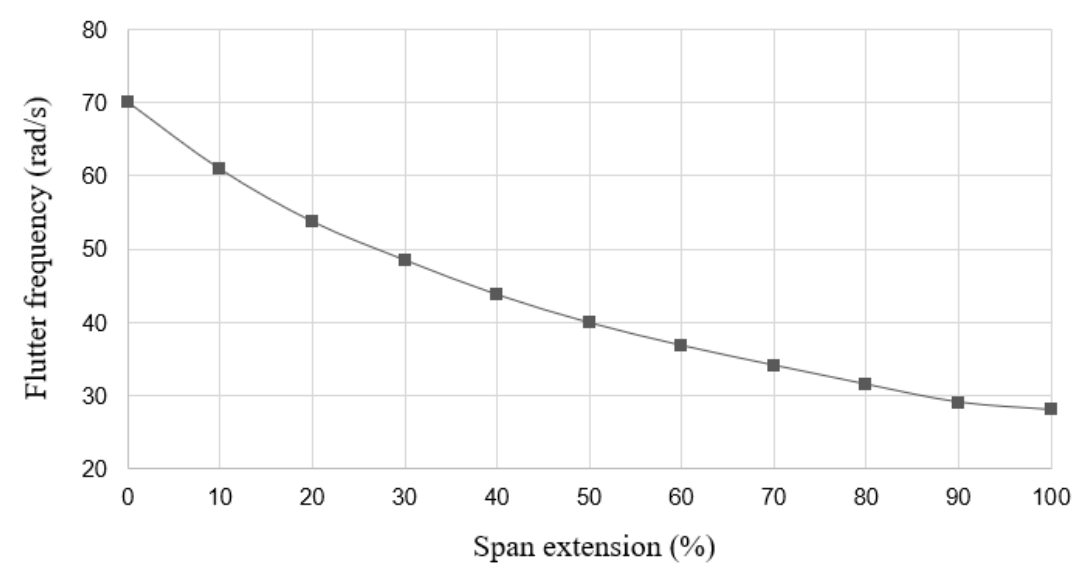

Figure 8: Variation of flutter frequency with span extension for Goland wing 
From the Figure 8, it can be seen that the flutter frequency also dramatically decreases as wing span extends, which is an expected outcome. As the wing span is morphed from fully retracted configuration to fully extended configuration, the flutter frequency decreases from $70.01 \mathrm{rad} / \mathrm{s}$ to $28.05 \mathrm{rad} / \mathrm{s}$. The reduction in flutter frequency between $0 \%$ wing extension and $10 \%$ wing extension is observed as 9.16 $\mathrm{rad} / \mathrm{s}$. On the other hand, the reduction in flutter frequency between $90 \%$ wing extension and $100 \%$ wing extension is found as $1.02 \mathrm{rad} / \mathrm{s}$.

\section{CONCLUSIONS}

The aim of this study is to analyze the flutter characteristics of VSMW oscillating in pitch and plunge motions under subsonic flight conditions. The flutter behavior of VSMW in different configurations are analyzed. The findings of case studies are presented as quantitatively and qualitatively for both two wing models. Based on the results of this study, the following expressions can be concluded:

(a) There is a significant difference in flutter values between fully retracted and fully extended wing configurations. The findings of this study support the idea that flutter values decrease as wing span increases.

(b) Another important finding is that flutter speed and flutter frequency reductions are relatively high at the initial stages of wing span extension.

These results have significant implications for understanding of how span extension affects the flutter behavior of aircraft. From these several analyses of telescopic span morphing wing, it can be concluded that the aeroelastic analysis has a vital role for morphing wing concept.

\section{REFERENCES}

[1] Bisplinghoff, R. L., Ashley, H., and Halfman, R. L. Aeroelasticity. Dover Publications Inc., New York, (1955).

[2] Previtali, F., E. Morphing wing based on compliant elements. Doctoral dissertation, ETH Zurich, (2015).

[3] Ajaj, R. M., Omar, F. K., Darabseh, T. T., and Cooper, J. Flutter of Telescopic Span Morphing Wings. International Journal of Structural Stability and Dynamics. (2019) 19(6):1950061.

[4] Gamboa, P., Santos, P., Silva, J., \& Santos, P. Flutter analysis of a composite variable-span wing. 4th international conference on integrity, reliability and failure, Funchal. (2013) 23-27.

[5] Seigler, T. M., Bae, J. S., and Inman, D. J. Flight control of a variable span cruise missile. ASME International Mechanical Engineering Congress and Exposition. (2004) 47063:565-574.

[6] Huang, R., \& Qiu, Z. Transient aeroelastic responses and flutter analysis of a variable-span wing during the morphing process. Chinese Journal of aeronautics. (2013) 26(6):1430-1438.

[7] Huang, C., Chao, Yang, Zhigang, Wu, \& Changhong, Tang. Variations of flutter mechanism of a span-morphing wing involving rigid-body motions. Chinese Journal of aeronautics. (2018) 31(3):490-497.

[8] Theodorsen, T. General theory of aerodynamic instability and the mechanism of flutter. Technical Report 496, NACA. (1934) 413-433.

[9] Yalcin, H. S., Arikoglu, A., and Ozkol, I. Free vibration analysis of circular plates by differential 
transformation method. Applied Mathematics and Computation. (2009) 212(2):377-386.

[10] Goland, M. The flutter of a uniform cantilever wing. Journal of Applied Mechanics. (1945) 12(4):A197-A208.

[11] Matter, Y. S., Darabseh, T. T., and Mourad, A. H. I. Flutter analysis of a viscoelastic tapered wing under bending-torsion loading. Meccanica. (2018) 53(15):3673-3691.

[12] Patil, M. J., Hodges, D. H., and Cesnik, C. E. Nonlinear aeroelastic analysis of complete aircraft in subsonic flow. Journal of Aircraft. (2000) 37(5):753-760.

[13] Patil, M. J., Hodges, D. H., and Cesnik, C. E. Nonlinear aeroelasticity and flight dynamics of highaltitude long-endurance aircraft. Journal of Aircraft. (2001) 38(1):88-94. 